\title{
PEMBUATAN KOMPOSIT ISOLATOR PANAS BERBAHAN SERAT KAPUK (CEIBA PENTANDRA) DAN POLIPROPILENA DENGAN METODE THERMAL BONDING
}

\author{
FABRICATION OF HEAT INSULATOR USING KAPOK FIBER (CEIBA \\ PENABDRA) AND POLYPROPYLENE BY THERMAL BONDING \\ METHOD
}

\author{
Bayu Pandu Dewanata ${ }^{1}$, Asril Senoaji Soekoco ${ }^{2}$ \\ 1. Lulusan Politeknik STTT Bandung, Indonesia \\ 2. Dosen Politeknik STTT Bandung, Indonesia \\ E-mail: tirtapanca3@gmail.com, asril-s@kemenperin.go.id,
}

\begin{abstract}
ABSTRAK
Komposit adalah suatu material yang terbentuk dari kombinasi dua material atau lebih melalui pencampuran yang tidak homogen, sehingga menghasilkan sebuah material dengan sifat baru yang berbeda dengan material pembentuknya. Perkembangan teknologi komposit saat ini tidak hanya mengkaji pada variasi struktur namun juga bahan baku yang lebih ramah lingkungan, salah satu bahan baku yang memiliki potensi besar adalah serat kapuk. Serat kapuk (ceiba pentandra) merupakan satu komoditi agrikultur yang tersedia dalam jumlah yang besar di Indonesia, Pada penelitian ini, serat kapuk digunakan bahan baku pembuatan insulator panas. Hal ini menjadi peluang untuk membuat produk dari pemanfaatan serat kapuk untuk meningkatkan harga jualnya.
\end{abstract}

Serat kapuk digunakan sebagai penguat dan jaring polipropilena digunakan sebagai matriks. Pembuatan komposit dari kedua bahan ini dilakukan dengan menggunakan metode hot press. Komposit dibuat dengan 3 komposisi kapuk dan polipropilena yang berbeda yaitu 25:75, 20:80 dan 15:85. Proses produksi dilakukan melalui penekanan dengan alat thermal bondingpada suhu $100^{\circ} \mathrm{C}$ dan durasi 4 kali 30 detik. Komposit yang telah terbentuk melewati pengujian suhu panas dan dingin dengan alat bantu berupa sensor suhu. Berdasarkan hasil pengujian ketahanan suhu panas dan dingin, diketahui bahwa komposit dengan komposisi 25:75 memiliki kemampuan paling baik untuk mempertahankan suhu ruangan. Persentase serat kapuk pada komposit berbanding lurus terhadap ketebalan komposit serta kemampuan komposit mempertahankan suhu dalam ruangan panas dan dingin.

Kata kunci: insulator panas, serat kapuk, polipropilena, komposit

\begin{abstract}
Composite is a material that is formed from a combination of two or more materials through an inhomogeneous mixing, resulting in a material with new properties that are different from the materials it is made of. The development of composite technology at this time not only about the structural variations but also explore the usage of environmentally friendly raw materials, one of the raw materials that has great potential is kapok fiber. Kapok fiber (ceiba pentandra) is an agricultural
\end{abstract}


commodity that is available in large quantities in Indonesia. In this study, kapok fiber is used as the material for making heat insulators. This is an opportunity to make products from the use of cotton fiber to increase the sales price.

Kapok fibers are used as reinforcement and polypropylene nets as a matrix. The composites of these two materials were made using the thermall bonding method. Composites were made with 3 different compositions of kapok and polypropylene, $25: 75,20: 80$ and 15:85. The production process is carried out by pressing with a thermal bondingat a temperature of $100^{\circ} \mathrm{C}$ and a duration of 30 seconds for 4 cycles. The composites that have been formed was tested through hot and cold temperature resistancy testing using a temperature sensor. According to the results, it is known that composites with a composition of 25:75 have the best ability to maintain room temperature. The percentage of kapok fibers in the composite is directly proportional to the thickness and the ability of the composite to maintain room temperatures in a hot and cold condition.

Keywords: heat insulator, kapok fibers, poltpropylene, composite

\section{PENDAHULUAN}

Serat kapuk (Ceiba Pentandra) merupakan salah satu produk perkebunan dengan julah produk yang cukup berlimpah saat ini di Indonesia, menurut data dari Badan Pusat Statistik diketahui bahwa produksi serat kapuk pada tahun 2012 dapat mencapai 64.000 ton/tahun dan ditanam pada lahan seluas 162.700 hektar. Jumlah kapasitas produksi kapuk yang besar ini sebagian besar hanya digunakan untuk bahan pengisi perlengkapan tempat tidur yang harga jual dari serat ini hanya Rp.3.000,00/kg. Hal ini merupakan peluang untuk membuat produk berbahan serat kapuk dengan nilai keekomian lebih tinggi.
Kapuk terdiri dari 64\% selulosa dan komponen lainnya berupa lignin serta pektin. Kapuk memiliki dinding serat yang sangat tipis, seratnya sangat lembut, rapuh, elastis dan daya lenting yang sangat baik. Daya lenting tersebut akan membuat kapuk dapat mengembang lalu terisi oleh udara yang terperangkap di dalamnya. Menurut Mikrajuddin Abdullah, udara yang terperangkap dapat menahan suhu dari luar untuk masuk ke dalam seperti halnya pada kain wol dan bulu burung. Penjelasan tersebut membuka peluang untuk memanfaatkan kapuk untuk dijadikan produk yang dapat menjaga suhu ruangan.

Kapuk memiliki sifat rapuh sehingga sulit untuk diaplikasikan, maka dari itu perlu ditambah material lain untuk 
mengikat kapuk agar dapat menjadi sebuah lembaran komposit yang kuat. Salah satu material yang bisa dijadikan material pengikat kapuk yaitu polipropilena. Polipropilena memiliki titik leleh yang relatif lebih rendah dibandingkan dengan poliester dan sejenisnya yaitu $130^{\circ} \mathrm{C}-171^{\circ} \mathrm{C}$, hal ini dapat memudahkan dalam proses thermal bondingdimana durasi proses akan lebih singkat dan lebih ramah energi. Kapuk memiliki sifat yang hampir sama dengan kapas, kapuk juga memiliki daya lenting yang baik, daya lenting tersebut akan membuat kapuk dapat mengembang lalu terisi oleh udara yang terperangkap di dalamnya. Udara yang terperangkap tersebut dapat mempertahankan suhu dari luar, sehingga memungkinkan kapuk dijadikan bahan yang digunakan untuk mempertahankan suhu ruangan.

Polipropilena adalah termoplastik yang terbuat dari monomer propilena yang memiliki sifat kaku, tidak berbau dan kuat. Sifat kuat ini akan sangat tepat jika dipadukan dengan sifat kapuk yang memiliki keunggulan dalam segi berat jenisnya yang relatif rendah dan memuliki daya lenting yang baik. Berdasarkan sifat kedua material tersebut maka dapat dilakukan penelitian dengan fokus pada pemanfaatan komposit serat kapuk (ceiba pentandra) dan polipropilena metode thermal bonding untuk menjaga suhu ruangan melalui pengaturan komposisi serat kapuk dan jaring polipropilena dan bagaimana hubungannya dengan sifat mekaniknya.

\section{METODA PENELITIAN}

Metode yang dapat dilakukan untuk menggabungkan kapuk dan polipropilena yaitu dengan metode thermal bonding. Pada metode thermal bonding, salah satu bahan baku yang digunakan harus bersifat termoplastik, sehingga dapat dipanaskan hingga mendekati titik leleh atau hingga bahan baku tersebut melunak, lalu diikuti proses pendinginan. Komposit dibuat dengan 3 macam komposisi kapuk dan polipropilena yang berbeda yaitu 25:75, 20:80 dan 15:85. Komposit menggunakan 6 lapisan jaring polipropilena dan 1 lapisan kapuk yang disusun dengan susunan, 3 lapisan jaring polipropilena di bagian luar dan 3 lapisan kapuk di bagian dalam. Proses produksi dilakukan melalui penekanan dengan mesin thermal bonding pada suhu $100{ }^{\circ} \mathrm{C}$ dan durasi 
4 kali 30 detik (setiap 30 detik dilakukan perubahan posisi komposit). Proses persiapan dan susunan bahan penyusun komposit dapat dilihat pada Gambar 3 dan Gambar 4.

\subsection{Alat dan Bahan}

Penelitian ini dilakukan dengan menggunakan peralatan untuk proses manufaktur komposit dan peralatan pengukuran suhu yaitu: thermocouple, oven pemanas, tomori refrigerator, tenso lab strength tester dan mesin thermal bonding dengan tekanan maksimal 30 bar dan suhu kerja masksimal hingga $240{ }^{\circ} \mathrm{C}$.

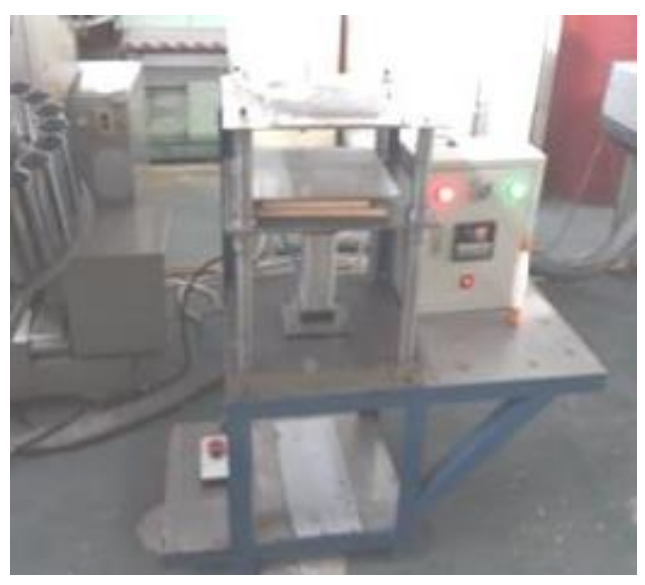

Gambar 1. Mesin hot press

Bahan yang digunakan pada peneltian ini adalah serat kapuk yang diperoleh di pasaran dan jaring polipropilena dengan spesifikasi sebagai berikut:

- Jeratan : pilar dan inlay

- Wale per inch : 8 wale per inch

- Course per inch : 3 course per inch

- Gramasi $\quad: 63 \mathrm{~g} / \mathrm{m}^{2}$

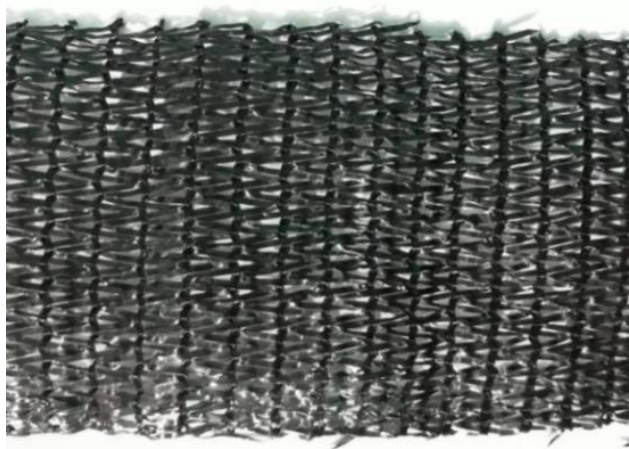

Gambar 2. Jaring polipropilena

\subsection{Pembuatan Komposit Kapuk dan Polipropilena}

Proses produksi komposit dapat dilakukan dengan beberapa metode, salah satunya adalah metode hot press. Pada penelitian ini produk komposit diproduksi melalui metode thermal bonding dengan langkahlangkah sebagai berikut:

1) Menyiapkan serat kapuk melalui proses pemisahan serat dan bijinya (orientasi serat kapuk yang digunakan tidak diatur searah / acak).

2) Menyiapkan jaring polipropilena dengan ukuran $23 \mathrm{~cm} \times 13 \mathrm{~cm}$, pemotongan jaring polipropilena 
terbagi menjadi dua macam yaitu jaring dengan lebar searah jeratan dan jaring dengan panjang searah jeratan. Gambar jaring polipropilena berdasarkan arah jeratannya dapat dilihat pada Gambar 3 di bawah ini.

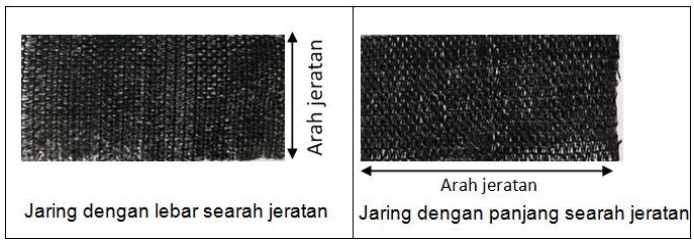

Gambar 3. Jaring berdasarkan arah jeratan

3) Mempersiapkan serat kapuk dengan tiga macam berat yang berbeda, yaitu berat kapuk dan polipropilena

dengan perbandingan $25: 75,20: 80$ dan 15:85.

4) Menyusun jaring polipropilena sebanyak tiga susun, susunan pertama yaitu jaring polipropilena dengan panjang searah jeratan, susunan yang kedua yaitu jaring polipropilena dengan lebar searah jeratan dan usunan yang ketiga yaitu jaring polipropilena dengan panjang ke arah jeratan pilar.

5) Meletakkan kapuk yang telah dicetak diatas susunan jaring polipropilena dan kembali meletakkan kembali susunan jaring polipropilena dengan susunan yang sama seperti sebelumnya diatas kapuk

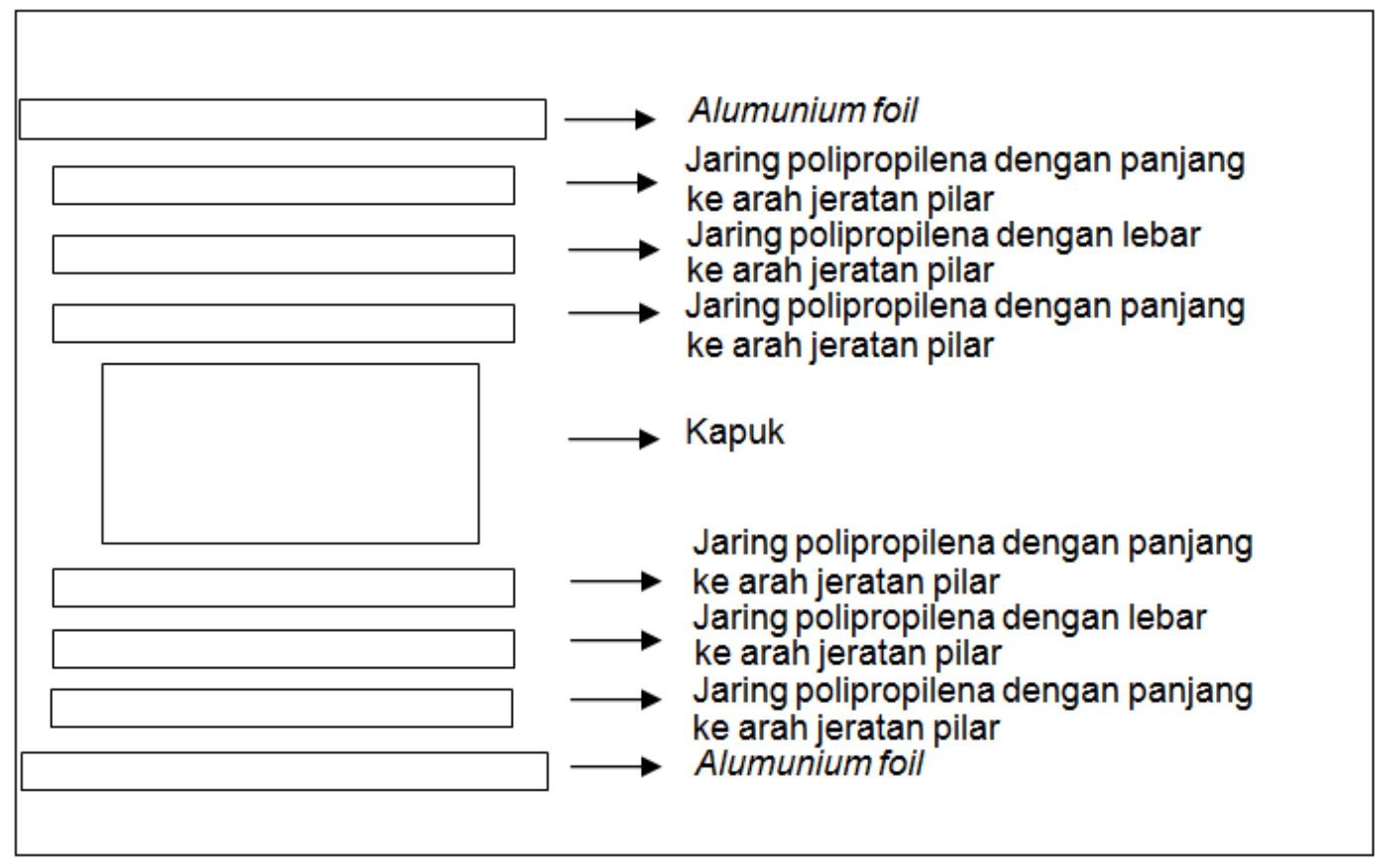

Gambar 4. Susunan dari komposit kapuk dan polipropilena 
6) Mengoperasikan mesin thermal bonding beserta kompressor yang terhubung pada mesin tersebut, mengatur tekanan pada mesin thermal bonding sebesar 2 bar, durasi tekanan selama 30 detik dan suhu proses $100{ }^{\circ} \mathrm{C}$ (hingga jaring polipropilena melunak dan mendekati temperatur leleh).

7) Meletakkan susunan komposit yang telah tersusun pada lower die dan mengukur suhu pada komposit dengan thermogun pada bagian upper die, apabila telah mencapai $100{ }^{\circ} \mathrm{C}$ maka mesin dapat dioperasikan.

8) Melakukan pemanasan komposit selama 4 kali 30 detik (setiap 30 detik dilakukan perubahan posisi komposit agar pemanasan dapat dilakukan secara bertahap dan merata).

9) Melakukan pengondisian selama 1 menit hingga komposit dalam suhu ruangan lalu lepaskan alumunium foil yang melekat pada komposit.

10) Melakukan pembuatan komposit dengan mengikuti langkah di atas sebanyak 10 kali untuk setiap variasi.

\subsection{Pengukuran Ketebalan}

Pengukuran ketebalan dilakukan untuk mengetahui ketebalan komposit yang dibuat berdasarkan komposisinya. Pengukuran ketebalan komposit dilakukan dengan langkah-langkah sebagai berikut:

1) Menyiapkan komposit, jangka sorong, penggaris dan marker.

2) Menandai posisi dari komposit yang akan dilakukan diuji ketebalannya menggunakan penggaris dan marker. Posisi pengujian ketebalan dilakukan pada 5 posisi sesuai pada Gambar 6 agar hasil pengujian dapat diperoleh sehomogen mungkin.

3) Melakukan pengukuran ketebalan dengan cara menjepit komposit dengan alat jangka sorong pada setiap posisi yang ditentukan. Proses penjepitan dilakukan dengan memperhatikan tekanan yang diberikan pada saat pengukuran agar tidak terjadi deformasi. 


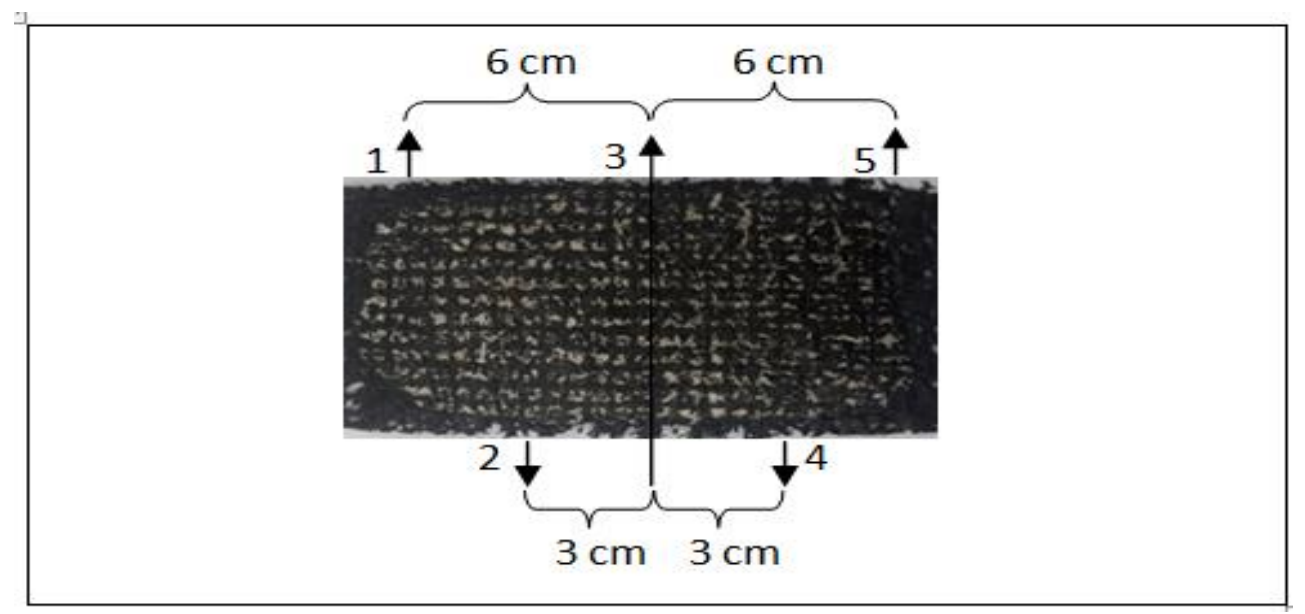

Gambar 5. Posisi pada komposit untuk pengukuran ketebalan

\subsection{Pengukuran Gramasi}

Pengukuran gramasi komposit menggunakan SNI 3801:2010 dengan tujuan untuk mengetahui berat dalam satuan gram setiap meter persegi. Pengukuran gramasi komposit dilakukan dengan langkah-langkah sebagai berikut:

1) Menyiapkan komposit, penggaris dan timbangan digital.
2) Mengukur lebar dan panjang komposit menggunakan penggaris

3) Mencatat lebar dan panjang komposit serta menghitung luas dari komposit.

4) Menimbang komposit dengan menggunakan timbangan digital kemudian, mencatat hasil dari penimbangan.

5) Menghitung gramasi dari komposit dengan rumus di bawah ini

$$
\text { Gramasi } \frac{g}{m^{2}}=\frac{\text { berat }(\mathrm{g})}{\text { Panjang }(\mathrm{m}) \times \operatorname{Lebar}(\mathrm{m})}
$$

\subsection{Pengujian Mempertahankan}

\section{Suhu pada Ruangan Panas dan}

Dingin

Pengujian yang dilakukan pada penelitian ini berupa aplikasi produk komposit yang dihasilkan untuk mempertahankan suhu pada ruangan panas dan dingin dilakukan melalui sebuah simulasi dimana komposit yang dihasilkan diletakan di dalam oven pemanas / lemari pendingin, 
pada bagian dalam komposit diletakan sebuah thermocouple pengukur suhu. Data hasil pengukuran suhu di bagian dalam komposit kemudian ditampilkan pada sebuah display yang dicatat perubahan setiap menitnya selama 25 menit (suhu di dalam oven pemanas / lemari pendingin sudah mulai stabil). Data perubahan suhu bagian dalam komposit tersebut kemudian dibandingkan dengan data perubahan suhu di dalam oven pemanas / lemari pendingin tersebut. Pengujian mempertahankan suhu pada ruangan panas dan dingin dilakukan dengan langkah-langkah sebagai berikut:

1) Mengoperasikan oven pada suhu $56,7^{\circ} \mathrm{C}$ dan lemari pendingin pada suhu $3^{\circ} \mathrm{C}$.

2) Menyalakan thermocouple dan letakkan sensor suhu pada bagian dalam komposit (pastikan bahwa posisi sensor suhu berada di tengah dari komposit dan tidak ada udara yang dapat keluar dari sisi-sisinya), hal ini dilakukan pada 5 buah komposit agar mendapatkan hasil yang akurat.

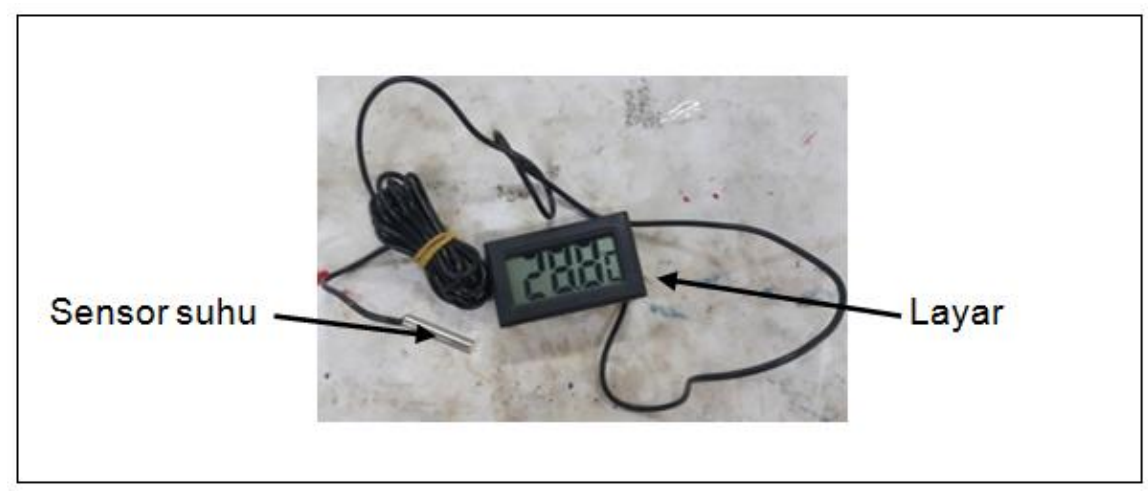

Gambar 6. Thermocouple

3) Mencatat suhu yang ada pada kelima layar thermocouple setiap menit selama 25 menit.

4) Melakukan langkah nomor 1

\subsection{Pengujian Kekuatan Tarik} sampai 3 dengan posisi yang berbeda-beda pada oven pemanas / lemari pendingin sebanyak lima kali untuk mendapatkan hasil yang akurat.

Pengujian kekuatan tarik dilakukan dengan menggunakan SNI 0276:2009 untuk menarik contoh uji sampai putus. Langkah-langkah dalam pengujian kekuatan tarik sebagai berikut: 
1) Mengoperasikan mesin dan komputer, kemudian membuka software pengujian pada komputer yang terhubung pada alat uji.

2) Menentukan jenis sampel yang diuji pada software, kemudian mengatur jarak jepit, kekuatan

tarik dan kecepatan penarikan pada software yang ada dikomputer.

3) Menyiapkan komposit dengan memotong komposit dengan ukuran $(2,5 \mathrm{~cm} \times 20 \mathrm{~cm})$, seperti pada Gambar 7 di bawah ini

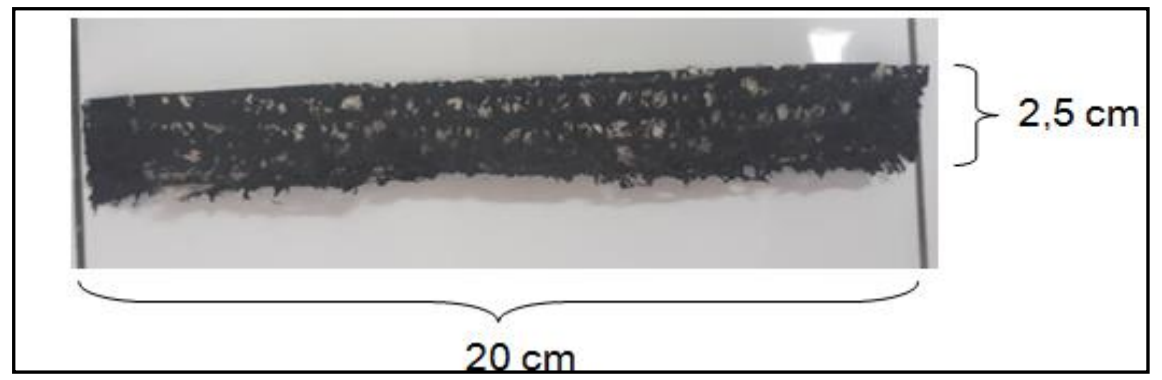

Gambar 7. Komposit untuk pengujian kekuatan tarik

4) Memasang komposit pada mesin dengan jarak jepit yang sudah ditentukan.

5) Mengencangkan penjepit komposit dimulai. pada masing-masing ujungnya

6) Menghentikan penarikan apabila dan menjalankan mesin sehingga komposit sudah patah seperti proses penarikan contoh uji pada Gambar 8 di bawah ini.

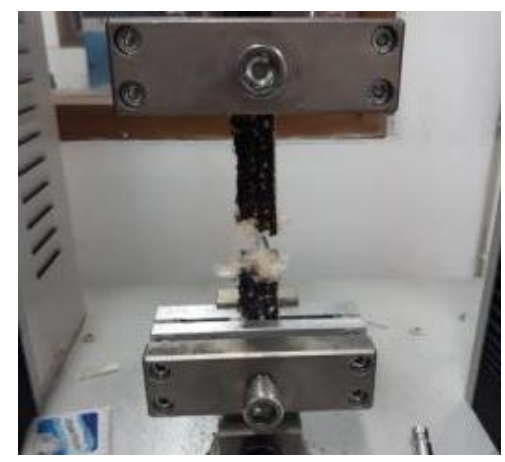

Gambar 8. Pengujian kekuatan tarik

7) Mencetak data hasil pengujian rekapitulasi dan analisa untuk setiap varasi komposit yang dihasilkan untuk kemudian dilakukan 


\section{HASIL DAN PEMBAHASAN}

Penelitian mengenai pemanfaatan komposit serat kapuk dan polipropilena yang digunakan untuk menjaga suhu ruangan dibuat menggunakan metode hot press. Komposit dibuat dengan 3 variasi komposisi kapuk terhadap polipropilena yaitu 25:75, 20:80 dan 15:85. Berdasarkan hasil percobaan yang dilakukan, dapat dikemukakan hal-hal sebagai berikut:

\subsection{Analisa Hasil pengujian}

\section{Ketebalan}

Berdasarkan hasil pengujian ketebalan komposit, didapatkan hasil untuk komposit dengan komposisi 25:75 memiliki ketebalan paling tinggi yaitu $0,71 \mathrm{~cm}$; lalu diikuti oleh komposit dengan komposisi 20:80 adalah $0,65 \mathrm{~cm}$ dan komposit dengan komposisi 15:85 adalah 0,62 cm. Grafik ketebalan komposit dapat dilihat pada Gambar 9 di bawah ini.

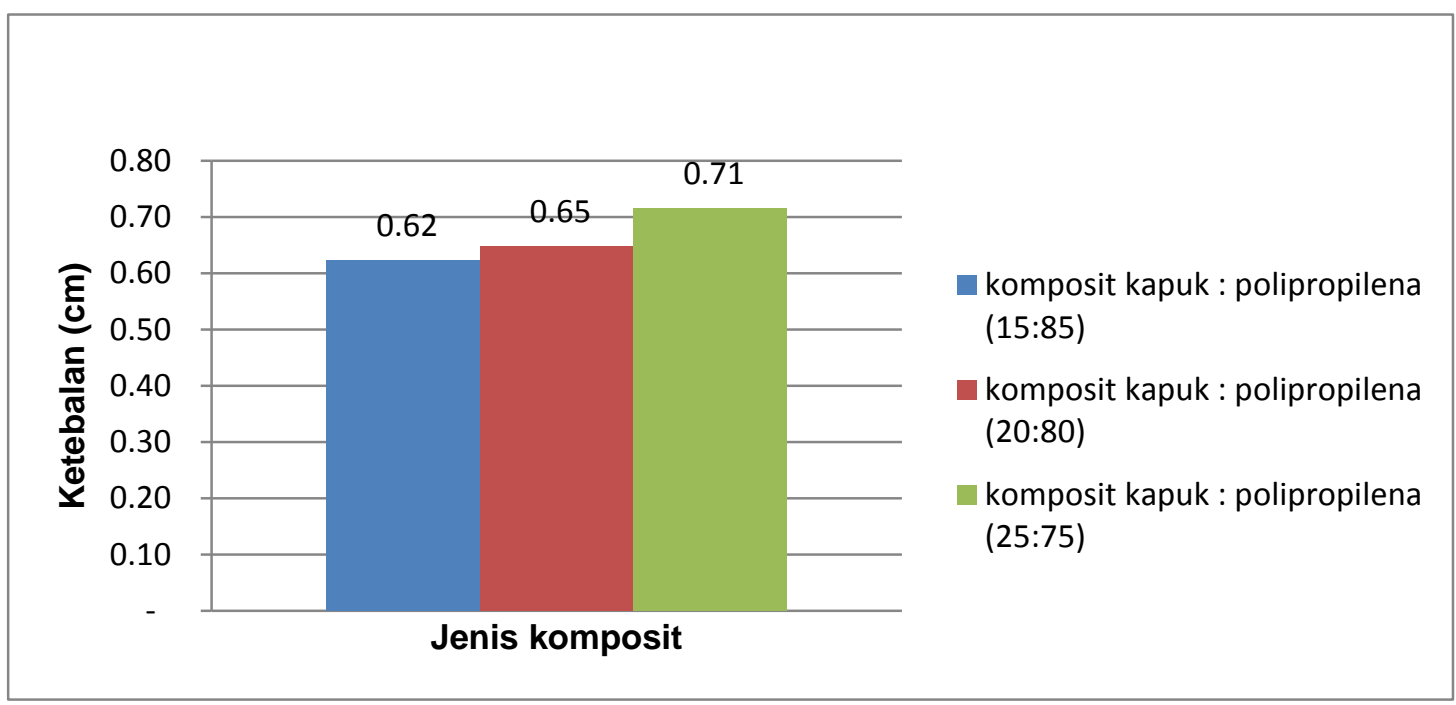

Gambar 9. Grafik ketebalan

Berdasarkan grafik di atas dapat struktur komposit dapat mengembang diketahui bahwa semakin tinggi dan rua (bulky). Semakin persentase serat kapuk pada sebuah mengembang dan rua sebuah komposit maka semakin tinggi komposit maka semakin banyak udara ketebalan komposit tersebut. Hal ini pada bagian dalam komposit tersebut. disebabkan karena daya lenting yang Hal ini mendatangkan dampak positif tinggi pada kapuk membuat bentuk untuk aplikasi insulator panas karena 
sifat udara akan meningkatkan kemampuan komposit tersebut dalam mengisolasi panas.

\subsection{Analisa Hasil Pengujian Gramasi}

Hasil pengujian gramasi komposit kapuk polipropilena, didapatkan gramasi rata-rata untuk komposit dengan komposisi 25:75 adalah $725,60 \mathrm{~g} / \mathrm{m}^{2}$, gramasi rata-rata komposit dengan komposisi 20:80 adalah $669,60 \mathrm{~g} / \mathrm{m}^{2}$ dan gramasi ratarata komposit dengan komposisi 15:85 adalah 633,40 g/m². Komposit dengan komposisi kapuk polipropilena 25:75 memiliki gramasi yang lebih besar, hal ini disebabkan faktor proses produksi komposit. Pada saat proses produksi komposit, massa dari polipropilena pada ketiga komposit dibuat sama besarnya karena jenis jaring polipropilena yang tersedia hanya satu jenis saja dan sulit untuk melakukan modifikasi pada jaring polipropilena tersebut. Dengan demikian, untuk mengubah variasi komposisi serat kapuk dan jaring polipropilena maka dilakukan penambahan massa serat kapuk sehingga semakin besar komposisi dari kapuk maka semakin besar massa serat kapuk tersebut. Hal ini menyebabkan berat total persatuan luas dari komposit yang dihasilkan menjadi lebih besar. Pengujian gramasi dilakukan sebagai data pendukung yang dapat digunakan pada saat pengujian performa komposit ini dalam menahan suhu di dalam ruangan panas dan dingin. Grafik gramasi komposit dapat dilihat pada Gambar 10 di bawah ini.

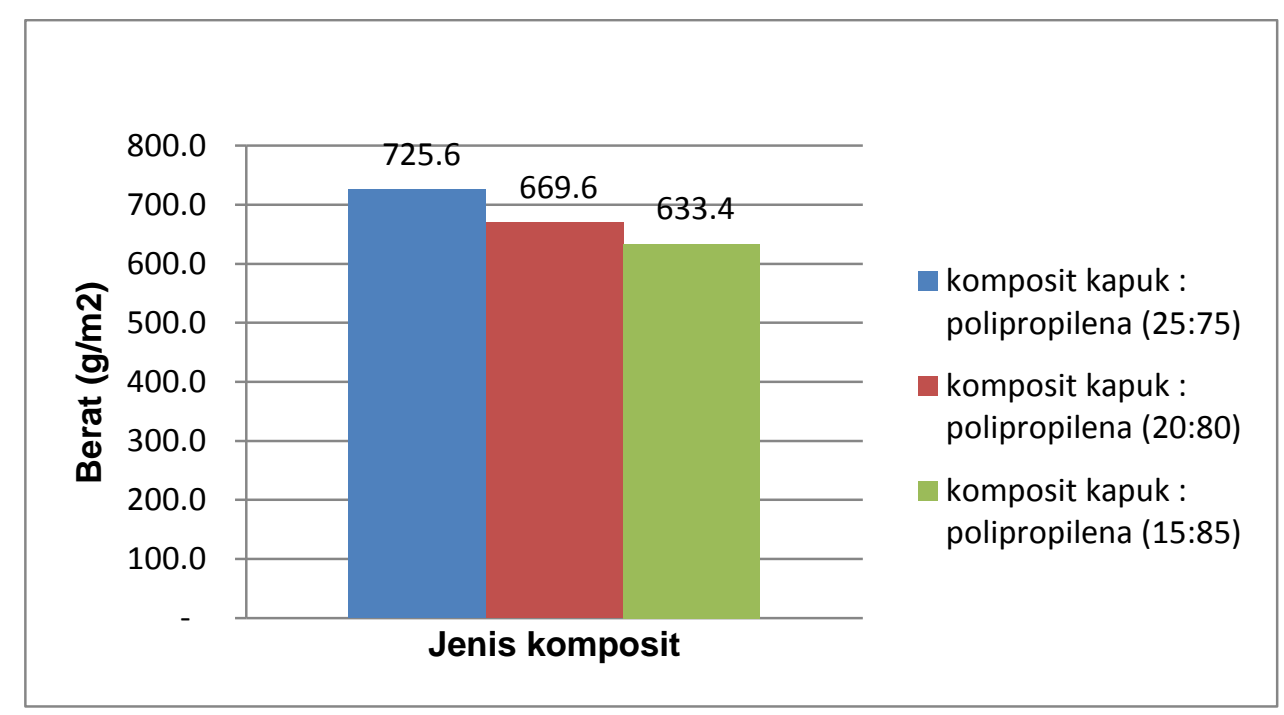

Gambar 10. Grafik gramasi 


\subsection{Analisa Hasil Pengujian}

\section{Mempertahankan Suhu pada}

\section{Ruangan Panas dan Dingin}

Pada pengujian mempertahankan suhu pada ruangan panas, komposit yang berada dalam ruangan terbuka memiliki suhu awal sebesar $28,8^{\circ} \mathrm{C}$, setelah itu dipanaskan dengan menggunakan suhu oven sebesar $56,7{ }^{\circ} \mathrm{C}$ selama 25 menit. Grafik pengujian suhu panas dapat dilihat pada Gambar 11.

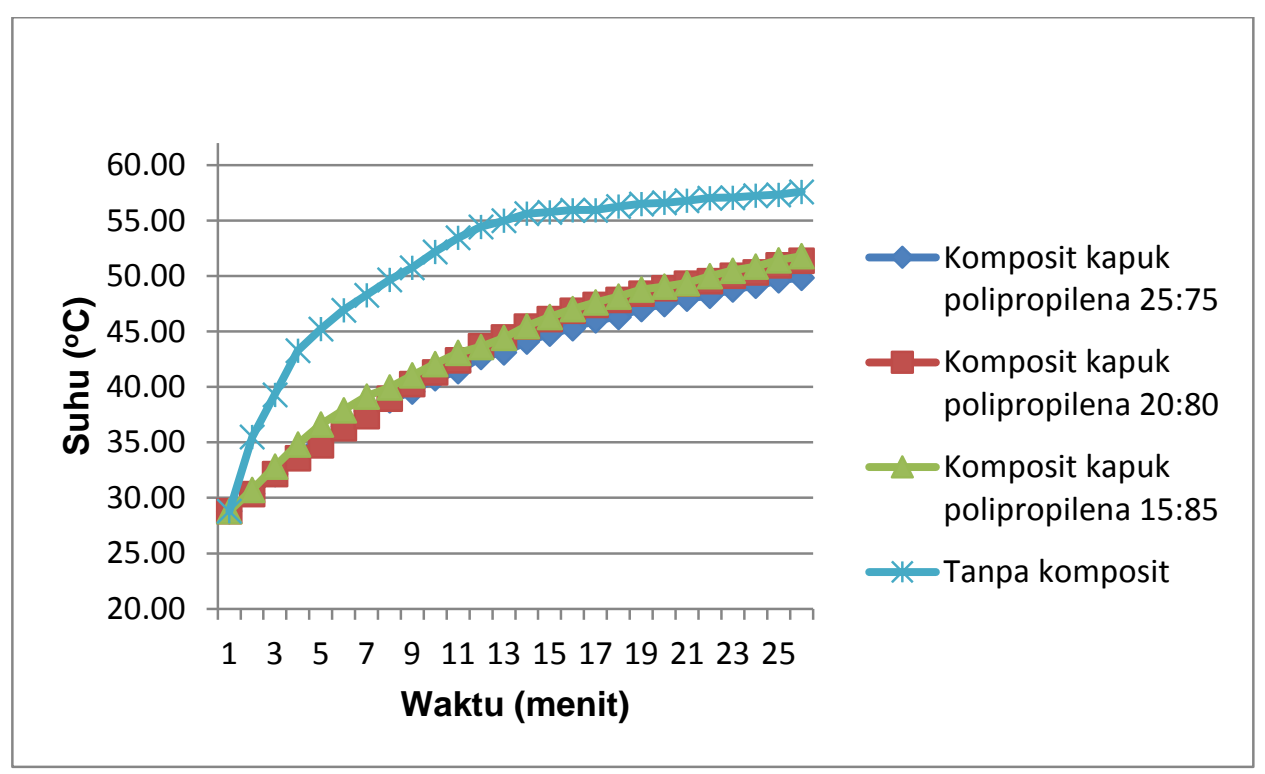

Gambar 11. Grafik pengujian mempertahankan suhu pada ruangan panas

Berdasarkan data pengujian dapat diketahui suhu rata-rata di bagian dalam komposit dengan komposisi 25:75 adalah $42,70{ }^{\circ} \mathrm{C}$, bagian dalam komposit dengan komposisi 20:80 adalah 43,54 ${ }^{\circ} \mathrm{C}$, bagian dalam komposit dengan komposisi 15:85 adalah $44,12{ }^{\circ} \mathrm{C}$ dan suhu rata-rata di dalam oven pemanas adalah $52,40^{\circ} \mathrm{C}$. Pada Gambar 11 dapat diketahui bahwa temperatur bagian komposit memiliki suhu yang lebih rendah dibandingkan dengan suhu bagian dalam oven pemanas. Hal ini disebabkan karena serat kapuk yang ada pada komposit memiliki daya lenting yang baik sehingga menciptakan rongga-rongga yang kemudian diisi oleh udara di dalamnya. Udara merupakan salah satu isolator panas terbaik yang mampu menahan perpindahan kalor dari bagian luar ke dalam dan begitupun sebaliknya. Hal tersebut selaras dengan persentasi komposisi serat kapuk pada komposit yang 
diproduksi, komposit dengan komposisi kapuk yang lebih banyak memiliki suhu lebih rendah dibandingkan dengan komposit yang memiliki komposisi kapuk lebih sedikit. Semakin besar komposisi serat kapuk pada komposit tersebut maka semakin baik dalam mempertahankan suhu pada ruangan panas.

Pada pengujian mempertahankan suhu pada ruangan dingin, pengukuran suhu awal komposit yang diletakan pada ruangan terbuka adalah $29,5{ }^{\circ} \mathrm{C}$, setelah itu komposit dimasukan ke dalam lemari pendingin dengan suhu $3{ }^{\circ} \mathrm{C}$ selama 25 menit. Berdasarkan data hasil pengujian dapat dihitung suhu rata-rata bagian dalam komposit dengan komposisi 25:75 adalah $16,10^{\circ} \mathrm{C}$, bagian dalam komposit dengan komposisi 20:80 adalah $15,73{ }^{\circ} \mathrm{C}$, bagian dalam komposit dengan komposisi 15:85 adalah $15,21{ }^{\circ} \mathrm{C}$, dan suhu rata-rata lemari pendingin dari sejak proses pendinginan dimulai hingga pengoperasian selama 25 menit adalah $11,54{ }^{\circ} \mathrm{C}$. Grafik pengujian suhu dingin dapat dilihat pada Gambar 12 di bawah ini:

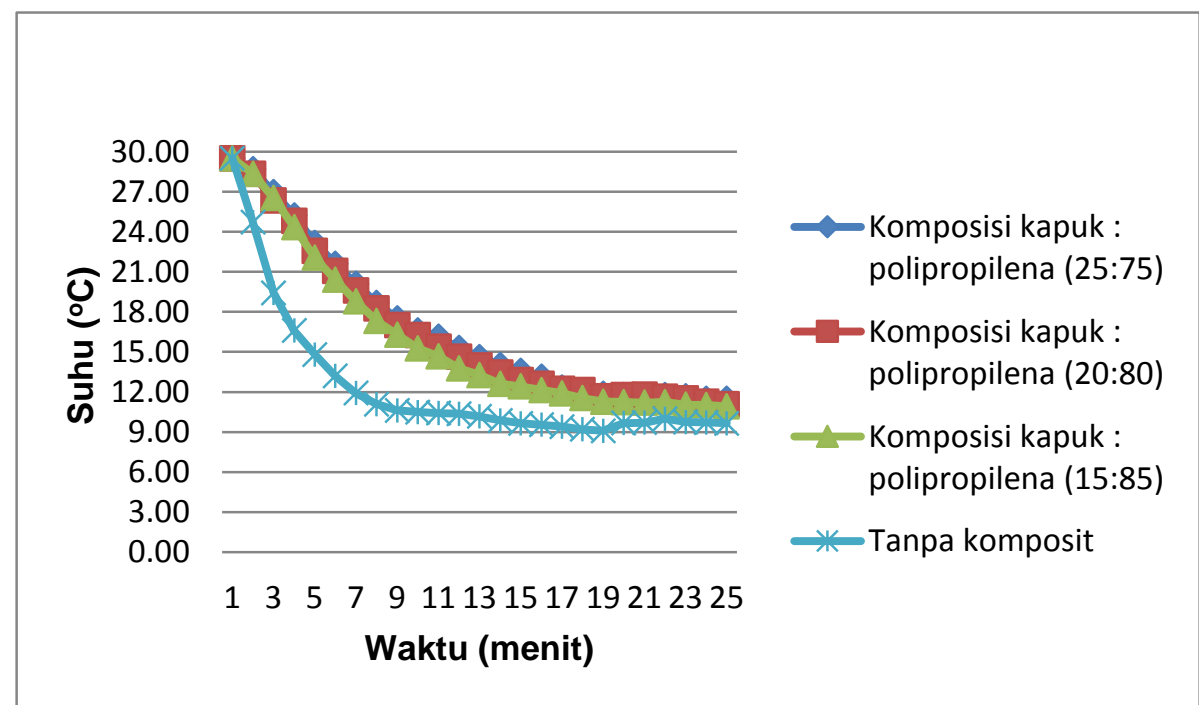

Gambar 12. Grafik pengujian mempertahankan suhu pada ruangan dingin

Hasil pengujian mempertahankan suhu pada ruangan dingin menuntun pada kesimpulan yang sama dengan hasil mempertahankan suhu pada ruangan panas. Suhu bagian dalam komposit memiliki suhu yang lebih tinggi dibandingkan dengan suhu ruangan pendingin dan semakin 
banyak persentase serat kapuk pada komposit tersebut maka semakin tinggi temperatur di bagian dalam komposit tersebut. Semakin banyak persentasi komposit maka semakin banyak rongga yang terbentuk pada komposit tersebut sehingga semakin banyak udara pada komposit tersebut dan semakin tinggi kemampuan komposit tersebut untuk menahan perpindahan kalor. Semakin baik kemampuan komposit dalam menahan perpindahan kalor maka semakin baik pula kemampuan komposit tersebut dalam aplikasi menjaga ruangan. Menjaga suhu ruangan yang dimaksud yaitu mengurangi perubahan suhu yang diberikan dari lingkungan luar ruangan. Dari pengujian suhu panas dan dingin dapat dilihat bahwa keduanya dapat mengurangi perubahan suhu yang diberikan. Hal ini membuka peluang untuk aplikasi tekstil teknik seperti roofing heat insulator yang bertugas untuk menjaga kenyamanan sebuah ruangan. Berdasarkan SNI 03-65722001, terdapat beberapa faktor yang mempengaruhi kenyaman termal salah satunya adalah temperatur udara pada ruangan. Temperatur udara di dalam ruangan diharapkan memberi rasa nyaman kepada penghuninya dengan mempertahankan temperatur di dalam ruangan dari temperatur di luar ruangan.

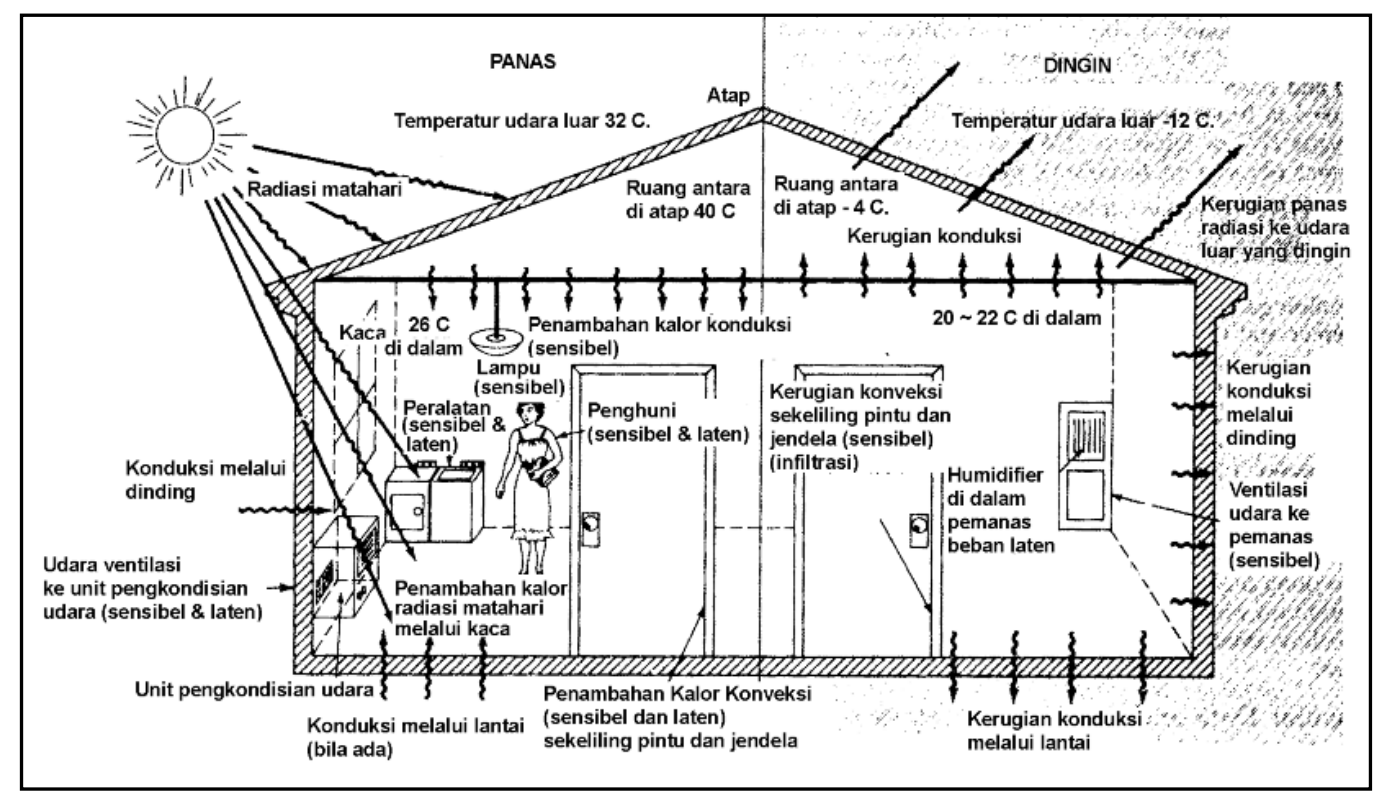

Gambar 13. Contoh pemanasan dan pendinginan pada ruangan (SNI 03-6572-2001) 


\subsection{Analisis Hasil Pengujian Kekuatan Tarik}

Berdasarkan hasil pengujian kekuatan tarik komposit kapuk polipropilena, didapatkan hasil untuk komposit dengan komposisi 25:75 adalah 2,59 kgf, komposit dengan komposisi 20:80 adalah 3,38 kgf dan komposit dengan komposisi 15:85 adalah 3,92 kgf. Grafik kekuatan tarik komposit dapat dilihat pada Gambar 14 di bawah ini.

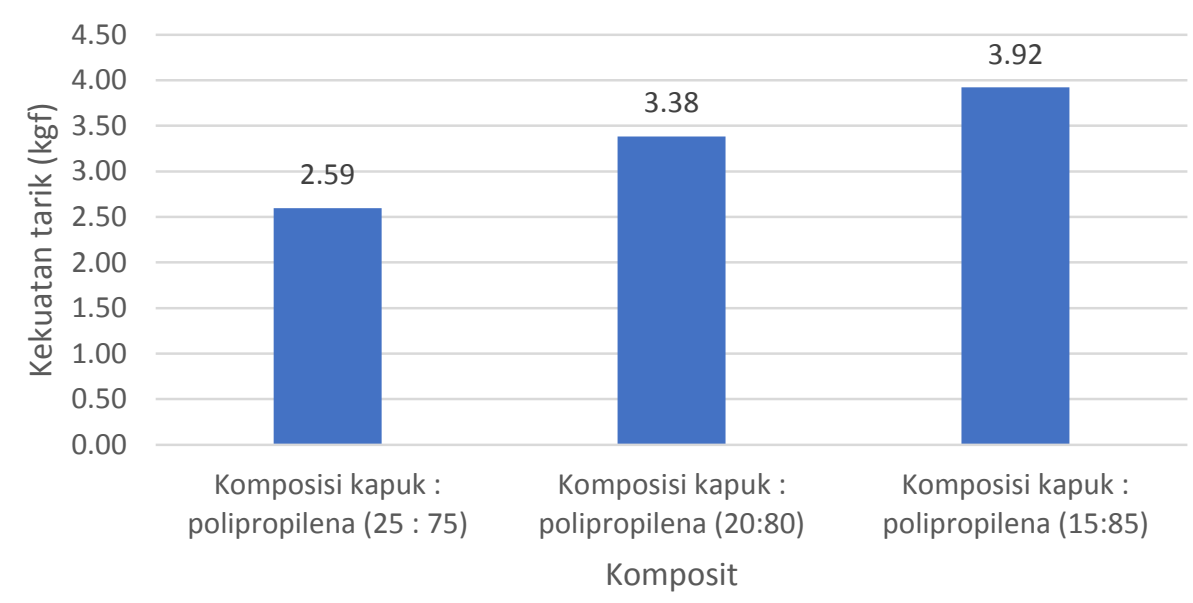

Gambar 14. Grafik kekuatan tarik

Komposit dengan komposisi kapuk polipropilena 15:85 memiliki kekuatan yang lebih tinggi dibandingkan dengan komposisi kapuk polipropilena 25:75 dan 20:80. Hal ini disebabkan karena jumlah komposisi polipropilena pada komposisi 15:85 lebih tinggi dibandingkan dengan komposit dengan komposisi 20:80 dan 25:75. Pada komposit kapuk polipropilena, jaring polipropilena memiliki fungsi untuk meneruskan tegangan ke dalam serat penguat sekaligus membentuk ikatan koheren antara serat yang satu dengan serat lainnya sehingga membentuk sebuah komposit yang sebih solid. Dengan demikian semakin tinggi komposisi dari polipropilena maka semakin tinggi juga kekuatan tarik dari komposit. Pengujian kekuatan tarik dilakukan sebagai data pendukung yang dapat digunakan pada saat handling produk jadi komposit pada saat aplikasi sebagai roofing atau heat insulator agar produk komposit ini tidak mudah sobek maupun rusak. 


\section{KESIMPULAN}

Berdasarkan penelitian pembuatan komposit isolator panas berbahan serat kapuk (ceiba pentandra) dan polipropilena dengan metode thermal bonding, dapat disimpulkan beberapa hal sebagai berikut:

1) Serat kapuk dan polipropilena dapat dimanfaatkan sebagai bahan baku pembuatan komposit yang berfungsi sebagai insolator panas.

2) Persentase serat kapuk pada komposit berbanding lurus terhadap ketebalan komposit serta terhadap kemampuan komposit mempertahankan suhu dalam ruangan panas dan dingin.

3) Pada penelitian ini, persentase serat kapuk pada komposit berbanding terbalik terhadap kekuatan tarik komposit yang dihasilkan.

\section{UCAPAN TERIMA KASIH}

Politeknik STTT Bandung melalui UP2M atas bantuan pendanaan sehingga penelitian ini dapat dilaksanakan.

\section{DAFTAR PUSTAKA}

1. Yulianti, N. A. (1993). Teknologi Busana. Yogyakarta: IKIP Yogyakarta. A Veerakumar \& N Selvakumar, (2012), A Preliminary Investigation on Kapok/Polypropylene Komposit Composite for Sound Absorption, Indian Journal of Fibre \& Textile Reseach Vol 37.

2. A S Soekoco, (2016), Serat Insulator Panas Ramah Lingkungan Berbahan Dasar Recycled Polypropylene Dari Limbah Tutup Botol Air Mineral, Jurnal Riset Industri Vol. 10 No. 3, Hal. 142-146.

3. Alexandr A.Berlin, dkk, 2015, Engineering Textile: Research Mtehodologies, Concepts and Modern Aplication.

4. Aruns Karthick, dkk, 2014, Development of Kapok/PP Blended Nonwovens for Thermal Insulation Application, Departement of Textile Technology, Anna University, Chennai, India.

5. BPS, (2012), Luas Area Tanam (Ha) dan Jumlah produksi Kapok, Indonesia.

6. Dipayan Das, Behnam Pourdeyhimi, 2014, Composite Nonwoven 
Materials Structure, Properties and Applications, The Textile Institute.

7. Hoechst Celanase, 1990, Dictionary of Fiber and Textile Technology.

8. Jonathan Oroh, Ir.Frans P.Sappu. MT, Romels, ST, MT. (2013), Analisis sifat mekanik material komposit serat sabut kelapa. Teknik mesin, Universitas Sam Ratulangi Manado.

9. James Rilatupa, (2008), Aspek kenyamanan termal pada pengkondisian ruang dalam, Universitas Kristen Indonesia, Jakarta.

10. Nation Convention of Textile Engieers $20^{\text {th }}$ and $21^{\text {nd }}$, (2014), Development of Kapok/PP Blended Komposit for Thermal Insulation Application.

11. Noni nopriantina, astuti, (2013). Pengaruh ketebalan serat pelepah pisang kepok (Musa paradisiaca) terhadap sifat mekanik material komposit poliester-serat alam, Jurnal fisika unand Vol.2, no. 3 Juli 2013. ISSN 2302-8491, Padang.

12. Rose Sinclair, 2015, Textile and Fashion Material, Design and Technology, The Textile Institute.

13. Shi Meiwu, Xiao Hong, Yu Weidong, (2009), The Fine Structure of the Kapok Fiber, Textile research journal.

14. SNI 0276:2009, Cara Uji Kekuatan Tarik Dan Mulur Kain Tenun, Badan Standarisasi Nasional (BSN).

15. SNI 03-6572-2001, Tekstil - Kain Tenun - Cara Uji Berat Kain Per Satuan Panjang dn Berat Kain Per Satuan Luas, Badan Standarisasi Nasional (BSN)

16. SNI 3801:2010, Tata Cara Perancangan Sistem Ventilasi dan Pengkondisian Udara Pada Bangungan Gedung. Badan Standarisasi Nasional (BSN). 